\title{
The metabolism of $\alpha$-linolenic acid by the foetal rat
}

\author{
By T. A. B. SANDERS AND D. J. NAISMITH \\ Department of Nutrition, Queen Elizabeth College, London $\mathrm{W8}{ }_{7} \mathrm{AH}$
}

(Received 30 January 1980 - Accepted 2 May 1980)

\begin{abstract}
The metabolism of [ $\left.1-C^{14}\right]$ linolenic acid $\left(18: 3 \omega_{3}\right)$ by the foetal rat was studied in vivo and in vitro. It is suggested that foetal brain has the capacity to convert linolenic to docosahexaenoic $\left(22: 6 \omega_{3}\right)$ acid to meet its requirements for docosahexaenoic acid.
\end{abstract}

The central nervous system of all mammals contains a relatively high proportion of docosahexaenoic acid (22:6 $\left.\omega_{3}\right)$, which is associated with the membrane lipids of neurones (Sun, 1973; Sinclair, 1975a). This fatty acid cannot be synthesized de novo in mammals but can be derived from linolenic acid $\left(18: 3 \omega_{3}\right)$ by way of alternating desaturation and chain elongation (Klenk \& Mohrhauer, I960; Mead et al. 1977) as follows:

$$
18: 3 \omega_{3} \stackrel{\Delta 6}{\rightarrow} 18: 4 \omega_{3} \rightarrow 20: 4 \omega_{3} \stackrel{\Delta 5}{\rightarrow} 20: 5 \omega_{3} \rightarrow 22: 5 \omega_{3} \stackrel{\Delta 4}{\rightarrow} 22: 6 \omega_{3}
$$

Thus docosahexaenoic acid can be obtained preformed in the diet from the consumption of foods of animal origin, especially offal and seafood, or can be derived from linolenic acid, which is found in edible vegetable oils, notably in soya-bean and rapeseed oils (Southgate \& Paul, 1978). The phase of neuronal multiplication occurs early in development before the brain growth spurt: in the rat it is almost complete by the second day after birth and in man by the end of the second trimester of pregnancy (Dobbing, 1970). Any interference with neuronal multiplication has a permanent effect as the brain does not exhibit catch up growth. Sinclair $(1975 b)$ suggested that rat milk provided the developing rat with a preformed source of docosahexaenoic acid for brain growth; radioactively labelled docosahexaenoic acid was shown to be more readily incorporated into brain lipids than the parent acid, linolenic. On the other hand, Dhopeshwarkar \& Subramaniam (1976) showed that the brain of the 13 -d-old rat pup could readily convert linolenic to docosahexaenoic acid. These studies, however, were made post-partum after the phase of neuronal multiplication is complete. Whether neuronal development is dependent on a maternal supply of preformed docosahexaenoic acid or whether the foetus can synthesize it from linolenic acid is unknown. We decided, therefore, to examine the capacity of the rat foetus to convert linolenic to docosahexaenoic acid.

\section{MATERIALS AND METHODS}

Littermate virgin rats (Charles Rivers CD) were mated and fed on a stock diet; day I of pregnancy was counted from the morning on which a mating plug was found. On the penultimate day of pregnancy (day 21 ) the animals were killed by cervical fracture and the foetuses removed. Littermate pups of similar weight were injected either intracranially or intraperitoneally with $\mathrm{I} \mu \mathrm{Ci}\left[\mathrm{I}-\mathrm{C}^{14}\right]$ linolenic acid $(\mathrm{I} 8: 3 \Delta 9,12,15$ all cis; specific activity $60 \mathrm{mCi} / \mathrm{mmol}$; Radiochemical Centre, Amersham) as the potassium salt in $10 \mu 1$ buffered isotonic saline $(8.9 \mathrm{~g}$ sodium chloride $/ 1, \mathrm{pH} 7 \cdot 4)$. The pups were kept alive for $\mathrm{I} h$ under a warm light then killed and dissected. Total lipids were extracted from the brains and livers of each pup with $5 \mathrm{ml}$ chloroform-methanol ( $\mathrm{I}: \mathrm{I}, \mathrm{v} / \mathrm{v}$ ) containing pentadecanoic acid as 
an internal standard ( $0.25 \mathrm{mg}$ for brain and $0.5 \mathrm{mg}$ for liver) and butylated hydroxytoluene $(0.5 \mathrm{mg})$ as an antioxidant. Methyl esters were prepared from the total lipid extracts by the method of Morrison \& Smith (1964). Portions of the total methyl esters were taken for determination of total radioactivity by liquid-scintillation counting using $5 \mathrm{~g}$ 2-(4'-tert butylphenyl)-S-( $4^{\prime \prime}$-biphenyl)-1,3,4-oxadiazole/ 1 toluene as scintillant and the external standard technique using a liquid-scintillation counter (Nuclear Enterprises). Methyl esters were separated and analysed by radiogas-liquid chromatography. Total lipids were also extracted from the homogenized carcasses using $20 \mathrm{vol}$ chloroform-methanol $(\mathrm{I}: \mathrm{I}, \mathrm{v} / \mathrm{v})$ and total radioactivity was measured by liquid-scintillation counting.

For measurements of $\Delta 6$ desaturation in vitro, littermate virgin rats (Charles Rivers CD) were mated and fed on a stock diet. On days 18, I 9,20 and 2 I of pregnancy, animals were killed and their foetuses removed. Foetal brains were dissected, weighed, pooled and homogenized with an equal volume of ice-cold medium (0.25 M-sucrose, $0.15 \mathrm{M}$-potassium chloride, $5 \mathrm{~mm}$-magnesium chloride, $4 \mathrm{I} \cdot 7 \mathrm{mM}$-sodium fluoride, $4 \mathrm{I} \cdot 7 \mathrm{~mm}$-phosphate buffer ( $\mathrm{pH} 7.4$ ), I.5 mM-glutathione, $0.33 \mathrm{~mm}$-niacin). Portions (200 $\mu \mathrm{l})$ of the homogenate were added to $3 \mathrm{ml}$ incubating medium at $37^{\circ}$, which was identical to the homogenizing medium except for the inclusion of $\mathrm{I} \cdot 4 \mathrm{mM}-\mathrm{ATP}, 0.87 \mathrm{mM}-\mathrm{NADH}, 0.06 \mathrm{mM}-\mathrm{CoA}$ SH (Ayala et al. I973) and $100 \mathrm{nmol}$ linolenic acid ( $3 \mathrm{nmol} \mathrm{I-C} \mathrm{C}^{14}$ labelled acid specific activity $60 \mathrm{mCi} /$ mmol; $97 \mathrm{nmol}$ unlabelled acid) in ro $\mu \mathrm{l}$ propylene glycol. The mixture was incubated aerobically for $30 \mathrm{~min}$ at $37^{\circ}$ on a shaking water-bath. The reaction was stopped by the addition of $2 \mathrm{ml}$ methanolic potassium hydroxide ( $\mathrm{I} 0 \mathrm{~g} \mathrm{KOH}$ dissolved in $5 \mathrm{ml}$ water and made up to $100 \mathrm{ml}$ with methanol) containing $125 \mathrm{mg}$ butylated hydroxytoluene $/ 1$ as antioxidant. The contents were vortex mixed under nitrogen and heated in sealed tubes at $85^{\circ}$ for $40 \mathrm{~min}$. On cooling, the mixture was acidified and lipids were extracted first with hexane $(2 \times 5 \mathrm{ml})$ then with diethyl ether $(5 \mathrm{ml})$. The combined extracts were dried over anhydrous sodium sulphate and methyl esters were prepared, after removal of the solvents under $\mathrm{N}_{2}$, by reaction with $2 \mathrm{ml}$ methanolic boron trifluoride-methanol-benzene $(35: 30: 35$, $\mathrm{v} / \mathrm{v}$ ) in a sealed tube under $\mathrm{N}_{2}$ on a boiling water-bath for $45 \mathrm{~min}$, using the method of Morrison \& Smith (1964). Methyl esters were analysed by radiogas-liquid chromatography.

Analyses by radiogas-liquid chromatography were made using a Pye 104 Gas-liquid Chromatograph (W. G. Pye, Cambridge) linked to an ESI Nuclear Radiogas Detector model 504 (ESI Nuclear, Reigate, Surrey). This instrument gave simultaneous curves for mass and radioactivity. Esters were separated on a $2 \cdot \mathrm{I} \mathrm{m} \times \mathrm{ro} \mathrm{mm}$ (o.d.) preparative glass column packed with $100 \mathrm{~g}$ Silar $10 \mathrm{C} / \mathrm{kg}$ Gas Chrom Q (100-120 mesh), which was obtained from Field Instruments, Twickenham, Middlesex, at 190\%. Argon-carbon dioxide (95:5, $\mathrm{v} / \mathrm{v}$ ) was used as the carrier gas. Identification of methyl esters was based on the comparison of retention times with known standards. Chain length was determined by hydrogenation (Christie, 1973) and the number of double bonds by argentation thin-layer chromatography (Dudley \& Anderson, 1975).

\section{RESULTS AND DISCUSSION}

The distribution of radioactivity in the foetal liver and brain $\mathrm{I} h$ after intraperitoneal or intracranial injection with [ $\left.\mathrm{I}-\mathrm{C}^{14}\right]$ linolenic acid is shown in Table $\mathrm{I}$. In the liver, a high proportion of the radioactivity was associated with saturated and monounsaturated fatty acids. This almost certainly arose from the $\beta$-oxidation of linolenic acid followed by the reincorporation of labelled acetate into fatty acids; from estimations of total radioactivity remaining in the carcasses it was evident that more than half the injected linolenic acid had been oxidized and presumably lost as $\mathrm{CO}_{2}$. Although a small proportion of saturated and monounsaturated fatty acid was labelled in the brain, this probably did not arise from $\beta$-oxidation in the brain itself. Labelled acetate has been shown to enter freely into the 
Table I. Distribution of radioactivity (\% total radioactivity in methyl esters) in brain and liver methyl esters $\mathrm{I} h$ following injection of $\mathrm{I} \mu \mathrm{Ci}\left[\mathrm{I}-C^{14}\right]$ linolenic acid $\left(\mathrm{I} 8: 3^{\omega_{3}}\right)$

(Mean values with their standard errors for four pups/group)

\begin{tabular}{|c|c|c|c|}
\hline \multirow[b]{2}{*}{$\begin{array}{r}\text { Site of injection } \\
\text { Fatty acid }\end{array}$} & \multicolumn{2}{|c|}{ Liver } & \multirow{2}{*}{$\begin{array}{c}\text { Brain } \\
\text { Intracranial }\end{array}$} \\
\hline & Intraperitoneal & Intracranial & \\
\hline $16: 0$ & $16 \cdot 7$ & $19 \cdot 2$ & 1.9 \\
\hline $16: 1$ & $4 \cdot 9$ & 3.7 & 0.4 \\
\hline $18: 0$ & $8 \cdot 3$ & 14.5 & 0.7 \\
\hline $18: 1$ & $9 \cdot 5$ & $1 \mathrm{I} \cdot \mathbf{3}$ & I.O \\
\hline $18: 3 \omega_{3}$ & $35 \cdot 3$ & $18 \cdot 0$ & $80 \cdot 0$ \\
\hline $18: 4 w_{3}$ & 7.0 & 8.0 & $2 \cdot 9$ \\
\hline $20: 3 \omega 3$ & I.I & - & 3.5 \\
\hline $20: 4 \omega 3$ & $4 \cdot 8$ & $6 \cdot 5$ & 2.5 \\
\hline $20: 5 \omega 3$ & $I 3 \cdot 1$ & 15.8 & 3.6 \\
\hline $22: 5 \omega_{3}$ & 0.4 & $1 \cdot 7$ & 1.8 \\
\hline $22: 6 \omega_{3}$ & 0.6 & $1 \cdot 6$ & $1 \cdot 4$ \\
\hline Total activity recovered (nCi) & $\begin{array}{l}90 \pm I \cdot 6 \\
20+I \cdot 3\end{array}$ & $19 \pm 1 \cdot 5$ & $113 \pm 36$ \\
\hline $\begin{array}{l}\text { Total activity as desaturation } \\
\text { products (nCi) }\end{array}$ & $29 \pm I \cdot 3$ & $6 \pm 0.6$ & $12 \pm 3 \cdot 3$ \\
\hline $\begin{array}{l}\text { Specific activity of total } \\
\text { fatty acids (nCi } / \mathrm{mg} \text { ) }\end{array}$ & IO $I \pm I \cdot 7$ & $2 \cdot 2 \pm 0.2$ & $17 \pm 5 \cdot 6$ \\
\hline
\end{tabular}

Table 2. Rates of $\Delta 6$ desaturation (nmol product/ $100 \mathrm{mg}$ brain per $h$ ) of linolenic acid in vitro by foetal rat brain on days 19,20 and 21 of pregnancy

(Mean values with their standard errors for six determinations)

Day of pregnancy

$\begin{array}{ll}19 & 38 \pm 2 \cdot 3 \\ 20 & 37 \pm 3 \cdot 0 \\ 21 & 43 \pm 1 \cdot 9\end{array}$

brain from the blood stream and to be incorporated into brain fatty acids (Mead et al.

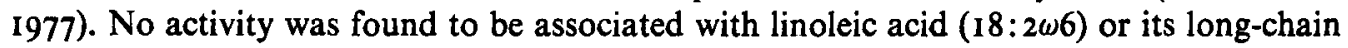
derivatives which was to be expected, as no interconversion occurs between the $\omega 6$ and $\omega_{3}$ series of polyunsaturated fatty acids (Holman, 1970).

A substantial proportion of the recovered radioactivity was associated with the longchain derivatives of linolenic acid in the liver lipids for both sites of injection. Likewise, when linolenic acid was injected intracranially, a significant proportion of the activity was associated with its long-chain derivatives in the brain. Total activity in the brain following intraperitoneal injection of labelled linolenic acid was too small $(\mathrm{I} \pm 0.3 \mathrm{nCi})$ to permit accurate analyses. The distribution of radioactivity among the long-chain derivatives in the brain was similar to that reported by Dhopeshwarkar \& Subramaniam (I976) in I3-d-old rat pups $8 \mathrm{~h}$ after intracranial injection with $3.85 \mu \mathrm{Ci}\left[\mathrm{I}-\mathrm{C}^{14}\right]$ linolenic acid.

The relatively high rate of $\Delta 6$ desaturation by foetal brain measured in vitro (Table 2) confirms that the brain has the capacity to convert linolenic acid to its long-chain derivatives. The presence of $\Delta 6$ desaturase activity was detected as early as day 18 of pregnancy but, owing to the minute size of the brain at that stage of development, some difficulty was encountered in measuring the activity. Consequently, the rates of desaturation on days I9, 20 , and 21 only are shown in Table 2 . While $\Delta 6$ desaturation may be rate-limiting for the conversion of linoleic $(18: 2 \omega 6)$ to arachidonic $(20: 4 \omega 6)$ (Sprecher, 1977), our results suggest that $\Delta 4$ desaturation is probably the rate-limiting step in the conversion of linolenic 
to docosahexaenoic acid, as previously proposed in man (Sanders et al. 1977; Sanders \& Naismith, 1979a). We were unable to measure the rates of $\Delta_{5}$ and $\Delta 6$ desaturation as radioactively-labelled eicosatetraenoic $\left(20: 4 \omega_{3}\right)$ and docosapentaenoic $\left(22: 5 \omega_{3}\right)$ were not available. It has been postulated that the foetal brain accumulates docosahexaenoic acid by a process of 'biomagnification' (Crawford et al. 1976): it was proposed that the maternal liver, the placenta, the foetal liver and brain each in turn augment the supply of docosahexaenoic acid derived from less unsaturated derivatives of linolenic acid. We have investigated the capacity of the rat placenta, from day I 8 to day 22 of pregnancy, to desaturate linolenic acid and have found the activity to be so low as to be barely measurable (Sanders \& Naismith, unpublished results). While foetal liver certainly does possess the capacity to convert linolenic to docosahexaenoic acid, it must also meet its own needs and those of other tissues (e.g. erythrocytes). The foetal rat brain increases in weight from approximately $75 \mathrm{mg}$ on day 18 to $200 \mathrm{mg}$ at birth on day 22 . This increase in weight is normally accompanied by the accumulation of $60 \mathrm{nmol}$ docosahexaenoic acid, which gives a mean hourly rate of accumulation of approximately $0.6 \mathrm{nmol}$. The rate of $\Delta 6$ desaturation by foetal brain greatly exceeded this value in vitro. Our findings suggest, therefore, that the foetal brain has sufficient capacity to convert linolenic to docosahexaenoic acid to meet its requirements for growth and is not dependent on a supply of preformed docosahexaenoic acid. This would also explain why the foetal brain is not protected from the adverse effects of an imbalance in the ratio, linoleic acid:linolenic acid in the maternal diet (Sanders \& Naismith, 1979b).

The authors are grateful to the Rank Prize Funds for a grant.

\section{REFERENCES}

Ayala, S., Gaspar, G., Brenner, R. R., Peluffo, R. O. \& Kunau, W. (1973). J. Lipid Res. 14, 296.

Christie, W. W. (1973). Lipid Analysis. Oxford: Pergamon Press.

Crawford, M. A., Hassam, A. G., Williams, G. \& Whitehouse, W. L. (1976). Lancet i, 452.

Dhopeshwarkar, G. A. \& Subramaniam, C. (1976). Lipids Ir, 67.

Dobbing, J. (1970). Am. J. Dis. Childh. x20, $41 \mathrm{I}$.

Dudley, P. A. \& Anderson, R. E. (1975). Lipids ro, ir 3.

Holman, R. T. (editor) (1970). In Progress in the Chemistry of Fats and Other Lipids, vol. 9, pp. 275, 607. Oxford: Pergamon Press.

Klenk, E. \& Mohrhauer, H. (1960). Z. Physiol. Chem. 370, 218.

Mead, J. F., Dhopeshwarkar, G. A. \& Gan Elepano, M. (1977). In Advances in Experimental Medicine and Biology, vol. 83, p. 313 [N. G. Bazan, R. R. Brenner and N. M. Guisto, editors]. London: Plenum Press.

Morrison, W. R. \& Smith, L. M. (1964). J. Lipid Res. 5, 600.

Sanders, T. A. B., Ellis, F. R. \& Dickerson, J. W. T. (1977). Lancet i, 953.

Sanders, T. A. B. \& Naismith, D. J. (1979a). Br. J. Nutr. 41, 619.

Sanders, T. A. B. \& Naismith, D. J. (1979b). Proc. Nutr. Soc. 38, 100A.

Sinclair, A. J. (1975a). Proc. Nutr. Soc. 34, 287.

Sinclair, A. J. (1975 b). Lipids 10, 175.

Southgate, D. A. T. \& Paul, A. A. (1978). McCance and Widdowson's The Composition of Foods. 4th ed. London: HMSO.

Sprecher, H. (1977). In Advances in Experimental Medicine and Biology, vol. 83, p. 35 [N. G. Bazan, R. R. Brenner and N. M. Guisto, editors]. London: Plenum Press.

Sun, G. Y. (1973). J. Lipid Res. 14, 656. 